INGENIERIA CIVIL

\title{
Síntesis de geopolímeros a partir de la activación alcalina de residuos de minería del oro
}

CIVIL ENGINEERING

\section{Synthesis of geopolymers from alkaline activation of gold mining wastes}

\author{
Erich Caballero*, Wilson Sánchez*, y Carlos A. Ríos*§ \\ *Escuela de Geología, Universidad Industrial de Santander, Colombia \\ §carios@uis.edu.co
}

(Recibido: 26 de Septiembre de 2013 - Aceptado: 11 de Diciembre de 2013)

\begin{abstract}
Resumen
Este trabajo presenta los resultados preliminares relacionados con el desarrollo de polímeros inorgánicos (geopolímeros) a partir de la activación alcalina de residuos de la minería de oro. La caracterización mineralógica y fisicoquímica de estos residuos de minería de oro muestra su gran potencial como fuente de precursores geopoliméricos como una alternativa razonable para el desarrollo de aglutinantes activados alcalinamente amigables con el medio ambiente. El proceso de geopolimerización es un camino viable para transformar estos residuos en materiales con alta resistencia mecánica, alta inercia química y alta durabilidad en el tiempo, dando valor agregado a los subproductos de la actividad minera.
\end{abstract}

Palabras clave: Activación alcalina, geología ambiental, geopolímeros, subproductos mineros.

\begin{abstract}
This paper reports preliminary results related to the development of inorganic polymers (geopolymers) from alkali-activation of gold mining wastes. Mineralogical and physicochemical characterization of these gold mining wastes shows their significant potential as geopolymeric source precursors as a reasonable alternative to the development of alkali-activated friendly environmental binders. Geopolymerization process is a viable way to transform these residues in materials with high mechanical strength, high chemical inertness and high durability over time, giving add value to the by-products of the mining industry.
\end{abstract}

Keywords: Alkaline activation, environmental geology, geopolymers, mining products. 


\section{Introduction}

The demand for Portland cement as a worldwide construction material increases as a result of population growth and economic development. By 2011, the global annual production of cement was about 3.4 million tonnes (USGS, 2012). However, its production generates the emission of toxic gases $\left(\mathrm{CO}_{2}, \mathrm{SO}_{2} \mathrm{y} \mathrm{NO}_{\mathrm{x}}\right)$ (Gartner, 2004). However, the cement industry is responsible to $5-7 \%$ of anthropogenic global $\mathrm{CO}_{2}$ emissions (Barceloand Kline, 2012). $\mathrm{CO}_{2}$ emissions are associated with decarbonization of limestone in the furnace of clinkerization (Puertas et al., 2006). The production of one tonne of Portland cement generates 0.55 tonnes of chemical $\mathrm{CO}_{2}$ and requires an additional 0.39 tonnes of $\mathrm{CO}_{2}$ in fuel emissions for baking and grinding, accounting for a total of 0.94 tonnes of $\mathrm{CO}_{2}$ (Gartner, 2004). It is known that the cement industry promotes the use of alternative materials contributing to the sustainable development with low $\mathrm{CO}_{2}$ emissions and proper use of natural resources, mainly due to the remarkable concern for environmental problems arising from global warming. To try to mitigate the issue of the huge amount of this type of gas, the cement industry has opted for the use of a number of additives.

The synthesis of geopolymers has resorted to the use of various industrial wastes, such as slag crystallized furnace volcanic ash (Sanjayan and Sioulas, 2000; Cheng and Chiu, 2003), fly ash (Swanepoel and Strydom, 2002; Bakharev, 2005; Fernández-Jiménez and Palomo, 2005; Temuujin et al., 2013), incinerator ash (Shih and Yokohama, 2003; Lancellotti et al., 2010; Luna-Galiano et al., 2011), aluminum recycling waste (Puertas et al., 1999; van Riessen et al., 2013), paper sludge and paper sludge ash (Hauser et al., 1999), ceramic wastes (Puertas et $a l ., 2006)$ and mining wastes (Singh and Garg, 2000; Pacheco-Torgal et al., 2008; Soares et al., 2008; Caballero and Sánchez, 2010; Zhang et al., 2011) as alternative materials in the manufacture of geopolymers, which has become a very effective way to reach, a large extent, this sustainable development. Notwithstanding this, many efforts are still being made to find new materials that can be used in the manufacturing process and production of cementitious products; the synthesis of geopolymers from mining waste turns out to be a good alternative as a long-term solution. In terms of global warming, the preparation of cementitious materials based geopolymers helps reduce $\mathrm{CO}$ emissions, without economic sacrifices for the industry, such that there is a total use of all materials and resources used in mining.

Pacheco-Torgal et al. (2007; 2008) show that it is possible to obtain a cementitious geopolymeric material from the muddy tailings of the Panasqueira tungsten mine (Portugal), proving that these wastes had a high content of muscovite and quartz, which in chemical terms means that they correspond aluminaand silica-rich materials. Based on the fact that geopolymerization processes can be result in aluminium silicate materials under highly alkaline conditions (Davidovits, 1994), the feasibility of using these residues in the synthesis of a friendly cementitious geopolymeric material of low cost long-term and very high mechanical and chemical resistancewas demonstrated.

This work is focused on evaluating the performance of cementitious materials based on inorganic polymers (geopolymers), obtained from the use of gold mining by-products. The chemical and mineralogical characterization of the mining wastesof interest in this study determines their possible use as an alternative raw material for preparing geopolymer-based mortars. The main contribution of this research to generate new knowledge refers to the mitigation of the environmental impact by transforming gold mining by-products in geopolymers for use as building materials.

\section{Materials and experimental procedure}

\subsection{Raw materials}

Type I Portland cement was used in this study as reference cement. It is manufactured by Holcim S.A. (Colombia), Nobsa (Boyacá). The raw material used as an additive in the preparation of geopolymer mortars corresponds to gold mine tailings from the La Baja Mine, which resultsafter the process of grinding and 
separation of sulfides from quartz feldspathic gneisses exhibiting silicification. It was sundried for 3 days, thenit was pulverized in a RETSCH Mortar Grinder RM 100 and sieved in order to use a particle size less than 62.5 microns for the preparation of the geopolymeric mortars. The sand used in the preparation of the different mixtures was extracted from the Chicamocha River (Santander). It was sun-dried for 3 days and sieved in order to use a uniform grain size. The gold mining wastes were activated with sodium hydroxide $(\mathrm{NaOH})$ in pellets of $98 \%$ purity and neutral sodium silicate $\left(\mathrm{NaSiO}_{3}\right) 42$ with molar ratio of $\mathrm{SiO}_{2}: \mathrm{Na}_{2} \mathrm{O} \approx 3.0$, which were commercially purchased from CONQUIMICA.

\subsection{Characterization of the raw materials}

The fineness of any cementing material affects its rate of hydration. Thus, the finer the material, the greater its rapidity of hydration, and, therefore, the greater the development of mechanical strength, as established by the test standard NTC 226 (ICONTEC, 1998). To carry out the determination of the fineness of the starting material, $100 \mathrm{~g}$ of sample were sieved through 200-mesh standard sieve. Then, the material that could pass through the mesh was removed from the bottom and weighed. The calculations were obtained from the following equation:

$$
F=100-R c
$$

Where, $F=$ fineness y $R c=$ corrected residue

To define $R c$, the following equation was used:

$$
R c=\frac{R s}{(100+C)}
$$

Where, $R s=$ retained residue in the 200-mesh and $C=$ sieve correction factor

In our case, the sieve correction factor (C) was zero, while the value of the corrected residue was $0.65 \mathrm{~g}$. Replacing these values in each of the expressions above, it was determined that the fineness of the gold mining waste is $99.35 \%$, a value very well accepted from the textural point of view, considering that the same procedure was performed on the type IPortland cement, which shows a fineness of $99.11 \%$.

The particle size analysis of the aggregate was conducted using the test standard E-123 INV (INVIAS, 2007), initially determining the weight of the granular fraction and separating the particles in different sizes $(1.180,0.600$, $0.425,0.250$ and $0.150 \mathrm{~mm}$ ) using sieves in decreasing order. Finally the weight of each retained fraction was determined by verifying that the sum of the weight retained on each sieve is equal to the initial weight of the granular fraction, with a tolerance of $0.5 \%$.

The characterization of the raw materials was performed using different analytical techniques, which are described below. The chemical composition of the raw materials was investigated using aEDX-800HSEnergy Dispersive X-ray Fluorescence Spectrometer, which has a $\mathrm{Si}(\mathrm{Li})$ solid state detector, rhodium $\mathrm{X}$-ray tube, and $10 \mathrm{~mm}$ collimator without filter. The quantification of the elements was performed using the method of fundamental parameters (FP) using the software DXP-700E version 1.00 Rel. 014.Mineral phases were studied by X-ray powder diffraction (XRPD) using a Rigaku D/MAX IIIB powder diffractometer working in Bragg-Brentano geometry and equipped with a $\mathrm{NaI}(\mathrm{Tl})$ scintillation detector. A $\mathrm{Cu}-\mathrm{K} \alpha$ radiation $(\lambda=1.5406 \AA)$, a graphite monochromator, a fixed Soller slit, a divergence slit of $1^{\circ}$ and a $0.3-\mathrm{mm}$ receiving slit were used. The diffractometer was operated over the range $2-70^{\circ}(2 \theta)$ at $40 \mathrm{kV}$ and $30 \mathrm{~mA}$, using step scan with a step size of $0.02^{\circ} 2 \theta$. Phase identification was performed using the crystallographic database Powder Diffraction File (PDF-2) from International Centre for Diffraction Data (ICDD). Full-pattern Rietveld refinement using RIQAS 3.1 program (MDI Inc.) was performed to quantify the amounts (wt $\%$ ) of phases. The raw materials were also examined by Fourier transformed infrared (FTIR) spectroscopy by using a Bruker FTIR Tensor 27 Spectrometer. The spectra were obtained in the $400-4000 \mathrm{~cm}-1$ region. Approximately $2 \mathrm{mg}$ of the sample plus $200 \mathrm{mg}$ of $\mathrm{KBr}$ were weighted out, milled and grounded in a mortar. The resulting mixture was then pressed into a pellet. 


\subsection{Synthesis of geopolymers}

In the synthesis of geopolymers, the standard test NTC 220 (ICONTEC, 1998) was followed. This standard states that for preparing 6 cement mortars, using molds of $50 \mathrm{~mm}$ side, the mass fractions must be compossed by 1 part of the cementitious material and 2.75 parts of the aggregate (sand). On the other hand, the ratio of water solution/cementious material should be 0.48 . Several percentages of the starting material $(50 \%, 70 \%, 80 \%, 90 \%)$ were added to the conventional cement in the synthesis process. In order to differentiate each of the resultant geopolymer, the code GEW-\%-8/16 was used, where the prefix GEW corresponds to the initials of the geopolymer and the names of the two main authors of this research paper; $\%$ is the proportion between the starting material and the type I Portland cement; 8/16 is the concentration of the $\mathrm{NaOH}$ solution used in the alkaline activation process. Therefore, the geopolymer GEW-50-8 corresponds to a synthesized material from a mixture of $50 \%$ of type I Portland cement $+50 \%$ of alkaline activated mining waste in a $\mathrm{NaOH}(8 \mathrm{M})+$ $\mathrm{Na}_{2} \mathrm{SiO}_{3}(16 \mathrm{M})$ solution. The relationship used in the activating solution $\mathrm{NaOH}: \mathrm{Na}_{2} \mathrm{SiO}_{3}$ was $1: 2$. Taking into account the NTC 220 standard, the experimental parameters for the preparation of geopolymers are summarized in Table 1.

\subsection{Technological tests}

The mechanical behavior of the synthesized material was measured by conducting compressive strength tests, whereas their performance and durability was evaluated under extreme conditions (attack by acids and sulfates, and high temperatures). In each test, the performance and durability of each geopolymer was compared with mortars made with type I cement Portland. Four mortars in each of the tests were used. This was done in order to be able to draw a representative average value. 672 mortars were prepared.

\subsubsection{Compressive strength tests}

These tests were conducted leaving each geopolymer to different storage times according

Table 1. Quantification of the materials according to the NTC 220 standard.

\begin{tabular}{|c|c|c|c|c|c|c|}
\hline $\begin{array}{c}G M W \\
(g)\end{array}$ & $\begin{array}{c}C P O \\
(g)\end{array}$ & $\begin{array}{l}\text { GMW/CPO } \\
\text { ratio }\end{array}$ & $\begin{array}{c}A \\
(g)\end{array}$ & $\begin{array}{c}\mathrm{NaOH} \\
8 \mathrm{M}(\mathrm{ml})\end{array}$ & $\begin{array}{l}\mathrm{Na}_{2} \mathrm{SiO}_{3} \\
8 \mathrm{M}(\mathrm{ml})\end{array}$ & Activating solution/GMW $+C P O+A$ \\
\hline \multicolumn{2}{|c|}{1 part } & & 2.75 parts & & & 0.485 parts \\
\hline 250 & 250 & 2.75 & 1375 & 81 & 161 & \multirow{4}{*}{ Test } \\
\hline 350 & 150 & 2.75 & 1375 & 81 & 161 & \\
\hline 400 & 100 & 2.75 & 1375 & 81 & 161 & \\
\hline \multirow[t]{5}{*}{450} & 50 & 2.75 & 1375 & 81 & 161 & \\
\hline & & & & & & Compressive strength ( 7,14 and 28 days) \\
\hline & & & & & & Attack with $\mathrm{H}_{2} \mathrm{SO}_{4}$ (4 weeks) \\
\hline & & & & & & Attack with $\mathrm{MgSO}_{4}$ (4 weeks) \\
\hline & & & & & & High temperatures \\
\hline $\begin{array}{c}G M W \\
(g)\end{array}$ & $\begin{array}{c}C P O \\
(g)\end{array}$ & $\begin{array}{l}\text { GMW/CPO } \\
\text { ratio }\end{array}$ & $\begin{array}{c}A \\
(g)\end{array}$ & $\begin{array}{c}\mathrm{NaOH} \\
16 \mathrm{M}(\mathrm{ml})\end{array}$ & $\begin{array}{l}\mathrm{Na}_{2} \mathrm{SiO}_{3} \\
8 \mathrm{M}(\mathrm{ml})\end{array}$ & $\begin{array}{l}\text { Relación solución activante / } \\
\text { GMW+CPO+A }\end{array}$ \\
\hline \multicolumn{2}{|c|}{1 parte } & & 2.75 partes & & & 0.485 parts \\
\hline 250 & 250 & 2.75 & 1375 & 81 & 161 & \multirow{4}{*}{ Test } \\
\hline 350 & 150 & 2.75 & 1375 & 81 & 161 & \\
\hline 400 & 100 & 2.75 & 1375 & 81 & 161 & \\
\hline \multirow[t]{5}{*}{450} & 50 & 2.75 & 1375 & 81 & 161 & \\
\hline & & & & & & Compressive strength $(7,14$ and 28 days $)$ \\
\hline & & & & & & Attack with $\mathrm{H}_{2} \mathrm{SO}_{4}$ (4 weeks) \\
\hline & & & & & & Attack with $\mathrm{MgSO}_{4}$ (4 weeks) \\
\hline & & & & & & High temperatures \\
\hline
\end{tabular}


to the account the NTC 220 standard. A polyethylene film completely isolated each of the specimens during curing times of 7 , 14,21 , and 28 days. At each of these times a total of 4 mortars were used in order to get a representative average of the test. These tests were conducted using a Shenck Trebel universal testing machine.

2.4.2 Compressive strength tests under extreme conditions of acidity, salinity and high temperatures

These tests intended to simulate a scenario where geopolymers were exposed to extremeconditions of acidity, salinity and high temperatures. They were conducted on geopolymers having cure times of 28 days. $\mathrm{H}_{2} \mathrm{SO}_{4}$ and $\mathrm{HNO}_{3}$ solutions as well as $\mathrm{MgSO}_{4}$ and $\mathrm{Na}_{2} \mathrm{SO}_{4}$ solutions were used, leaving the geopolymeric specimens immersed for 7, 28 and 56 days. Compressive strength tests at high temperature were carried out at $200,400,600,800$ and $1000{ }^{\circ} \mathrm{C}$ for $2 \mathrm{~h}$.

\section{Results anddiscussion}

\subsection{Mineralogy and geochemical properties of the raw materials}

\subsubsection{Gold mining waste}

Figure 1a illustrates the IR spectrum characteristic of the geological material (gold mining waste) used in the preparation of geopolymers. Each of the crystalline phases identified is within the wavelength range of of 500 to $3500 \mathrm{~cm}^{-1}$. The occurrence of sulfides and oxides in the IR spectrum is observed in the wavelength range of $300-1000 \mathrm{~cm}^{-1}$ (Perez, 2008). On the other hand, quartz may be easily identified within the region between 1000 and $1500 \mathrm{~cm}-1$ (RojasLópez et al., 2006). Muscovite can be identified in the wavelength range of $1400-2200 \mathrm{~cm}^{-1}$, although it shows a poor performance in the IR spectrum (Riaza et al., 1994). The carbonates can be identified in a wide range of wavelengths (750-3500 $\left.\mathrm{cm}^{-1}\right)$. According Riaza et al. (1994),
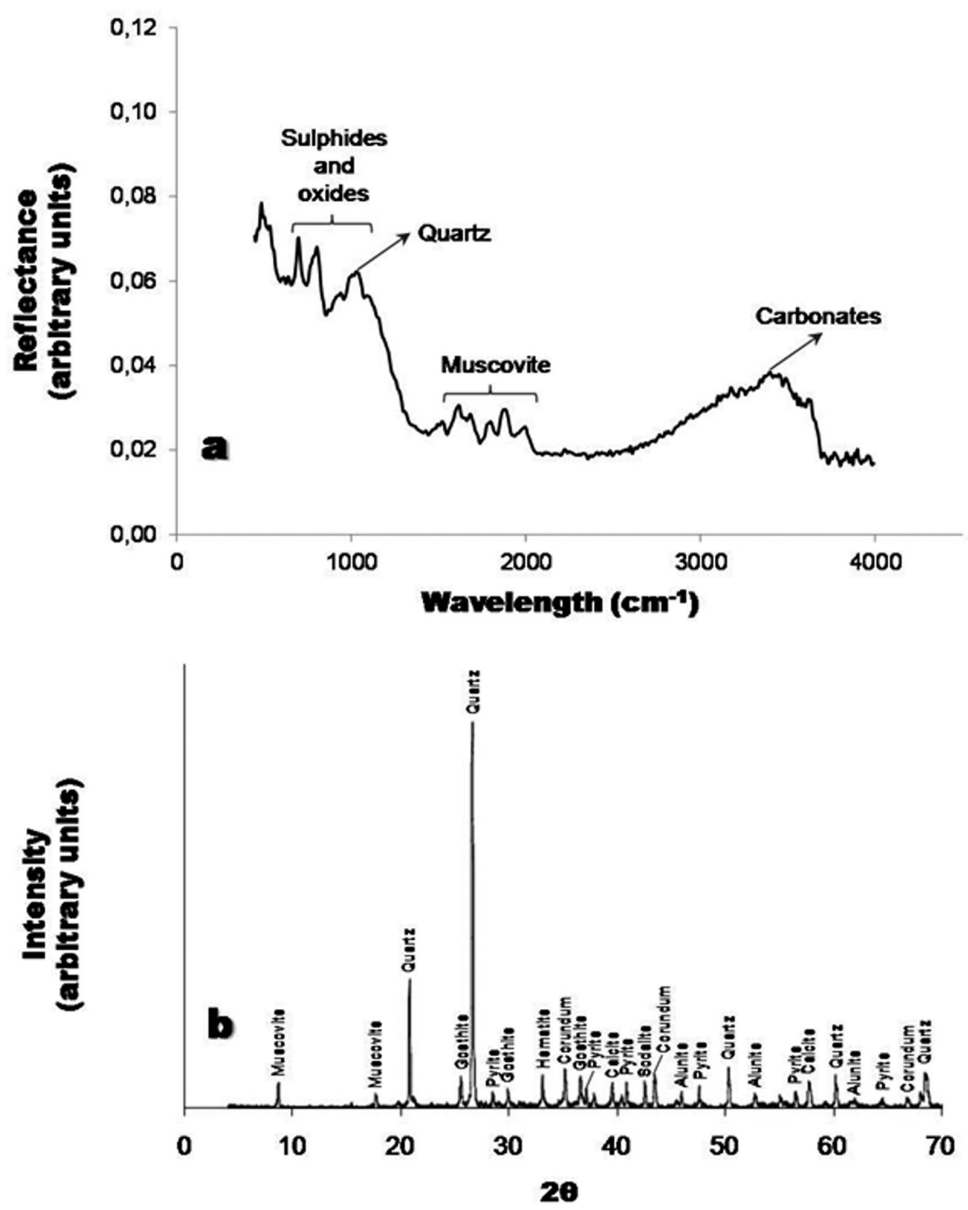

Figure 1. (a) IR spectrum and (b) X-ray diffraction pattern of the gold mining waste. 
their behavior resembles that of quartz and must always be greater than that of micas.

The qualitative analysis by X-ray diffraction (Figure $1 b)$ of the gold mining waste reveals that this geomaterial consists of different crystalline phases (quartz, muscovite, pyrite, alunite and goethite). $\mathrm{ON}$ the other hand, the quantitative analysis reveals in general terms, a compositional predominance of quartz $(52.9 \%)$, muscovite $(12.9 \%)$, pyrite $(6 \%)$, alunite $(6.1 \%)$ and goethite $(4.1 \%)$.

The chemical composition of the mining waste, which was determined by X-ray fluorescence, reveals a predominance of $\mathrm{SiO}_{2}(61.8 \%)$. It is well known that a geopolymerization process is successfully performed in the vast majority of materials in the presence of alumino-silicate compounds (Davidovits, 1994), and the $\mathrm{SiO}_{2} /$ $\mathrm{A}_{12} \mathrm{O}_{3}$ ratio is a parameter that influences not only the preparation of a geopolymer material but also its performance and durability (Duxson, 2006). The mining waste has a $\mathrm{SiO}_{2} / \mathrm{Al}_{2} \mathrm{O}_{3}$ ratio of 6.6, which is very high compared to the range of 3.03.8 proposed by Duxson et al. (2007) to perform successfully a geopolymerization process.

\subsubsection{Aggregate}

The aggregate used in the preparation of geopolymers corresponds to a very coarse-grained $(1.19 \mathrm{~mm})$ arkosic sand size, which presents particles predominantly non-spherical sub-angular to sub-rounded, and is composed of quartz, feldspar and lithic fragments. Figure 2a illustrates the characteristic IR spectrum of the aggregate, which reveals different mineral phases within the range of wavelengths between 800 and 3800 $\mathrm{cm}^{-1}$. Taking into account the response of quartz ( $\lambda=1000$ to $1500 \mathrm{~cm}^{-1}$ and high reflectances) and muscovite $\left(\lambda=1400\right.$ to $2200 \mathrm{~cm}^{-1}$ and low reflectances) in the IR spectrum, it is proceeded to the identification of feldspars and lithic fragments. Although feldspars exhibit a behavior similar to that of quartz (Riaza et al., 1994), it is possible to distinguish them, since the former will be within
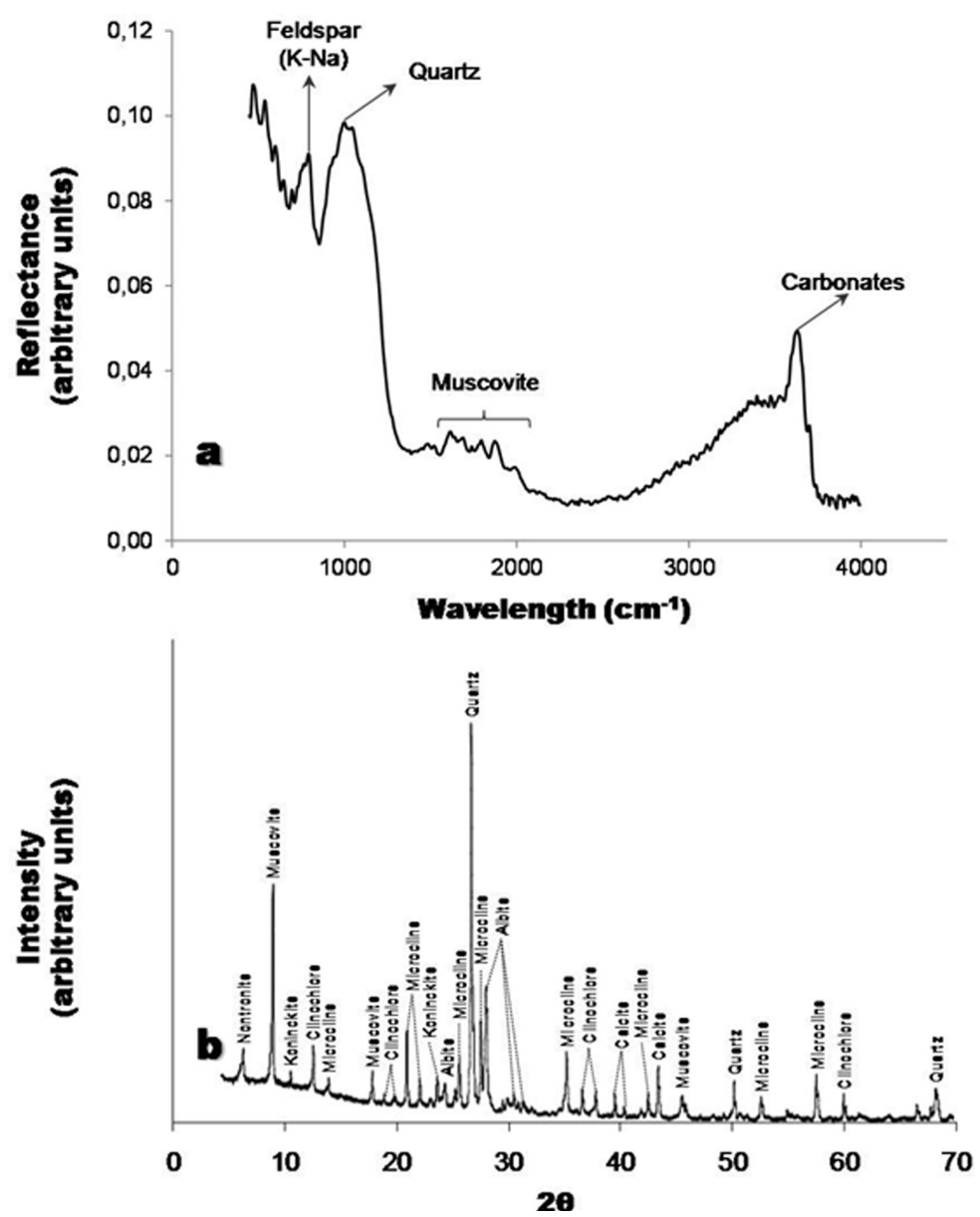

Figure 2. (a) IR spectrum and (b) X-ray diffraction pattern of the aggregate. 
a shorter wavelength range $\left(800-900 \mathrm{~cm}^{-1}\right)$. The rock fragments may be a special case due to their difficulty during identification. Riaza et al. (1994) consider that to identify any type of rock in the IR spectrum, it is necessary to emphasize particularly on the mineralogical composition of the sample. The heterogeneous nature of the lithic fragments in the aggregate, of difficult determination, was resolved due to the atypical behavior observed in the wavelength of $3800 \mathrm{~cm}^{-1}$, which is characteristic of lithic fragments.

The apparent mineralogical homogeneity of the arkosic sand, was counter-argued with the qualitative and quantitative analysis by X-ray diffraction of the crystalline phases, which showed a group of minerals that could not be seen in the macroscopic description. The $\mathrm{X}$-ray diffraction pattern (Figure $2 \mathrm{~b}$ ) shows the presence of clinochlore $(6.3 \%)$, a typical mineral of some metamorphic rocks. This percentage would be associated with the high percentage content of lithic fragments found in the aggregate, taking into account that this is mainly
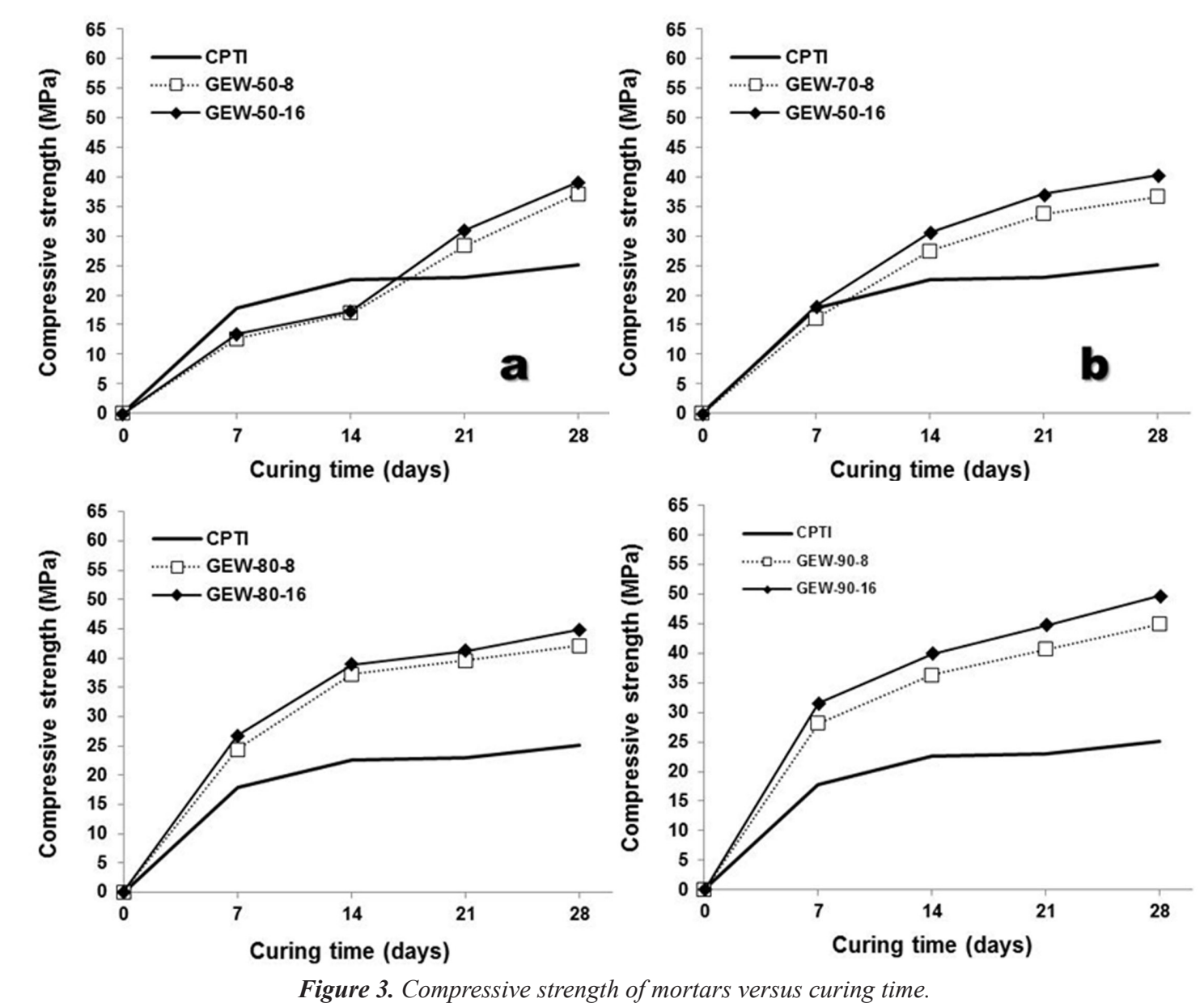

Figure 3. Compressive strength of mortars versus curing time.

constituted of relict igneous and metamorphic rocks. Quantitative analysis reveals the presence of albite type plagioclase (30.7\%) andmicrocline type potassium feldspar (18.7\%).

Results from X-ray fluorescence show that there is a pronounced predominance of aluminiumsilicate compounds $\left(\mathrm{SiO}_{2} 68.0 \%\right.$ and $\mathrm{Al}_{2} \mathrm{O}_{3} 18.6 \%$, respectively). Given that the $\mathrm{SiO}_{2} /$ $\mathrm{Al}_{2} \mathrm{O}_{3}$ ratio is 3.6 , the probability of success during a geopolymerization reaction is one more time sustained as a chemical type constrain. This value is within the range of success in the geopolymerization reaction proposed by Duxson et al. (2007).

\subsection{Compressive strength, performance and durability tests}

\subsubsection{Compressive strength}

The values of compressive strength at which the synthesized mortars were tested are summarized in Figure 3. There is a constraint

cof 

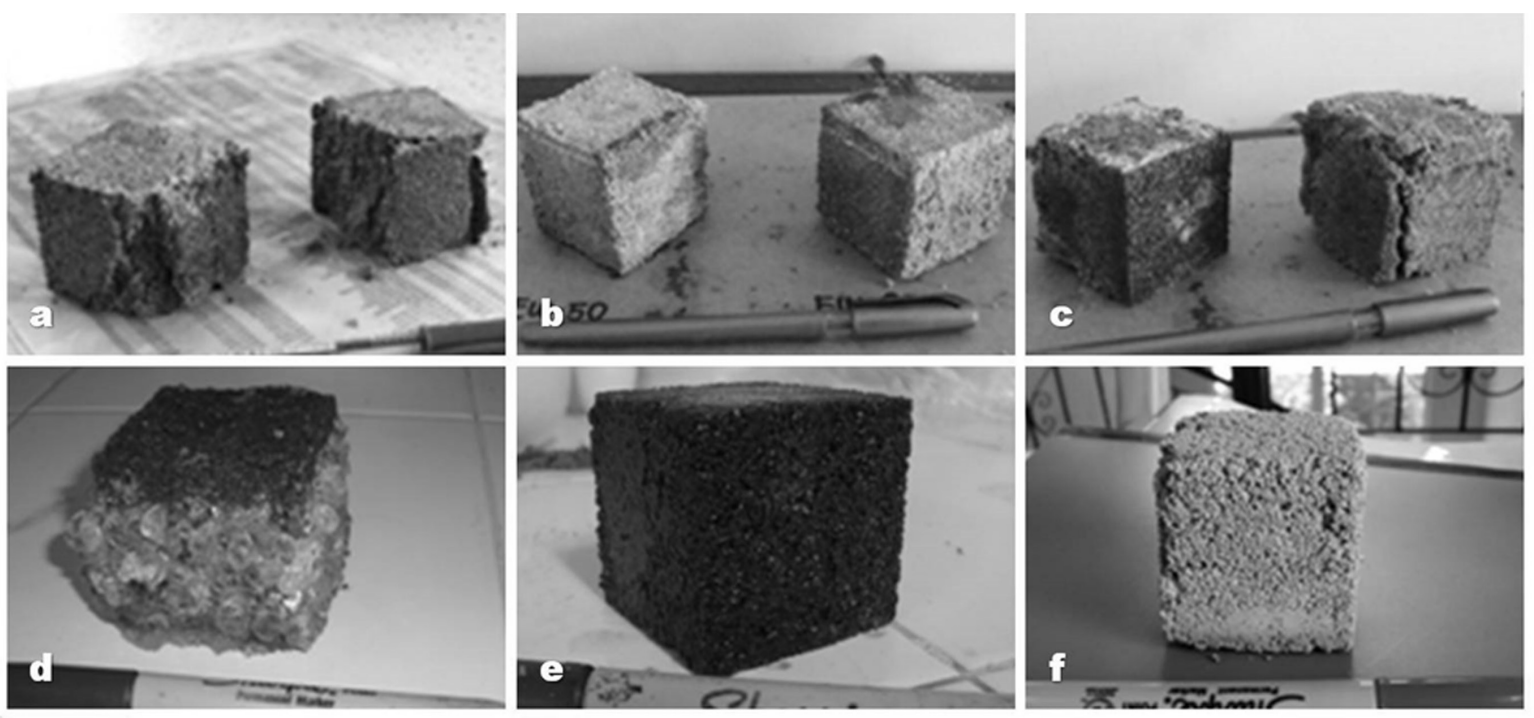

Figure 4. General trends on the mechanical strength, and performance and durability of geopolymers: (a) fragile fracture to compressive strength, after of attack with (b) sulfuric acid and (c) nitric acid, (d) crystallization of geopolymer in $\mathrm{Na}_{2} \mathrm{SO}_{4}$ solution, (e) physical hardening of geopolymer after immersion in $\mathrm{MgSO}_{4}$ solution, (f) change in tone and cohesion of geopolymer at high temperatures.

of chemical type that controls the performance of the geopolymers. It shows that when the concentration of the $\mathrm{NaOH}$ solution into the activating solution was increased, there is a better performance of the specimens in the compressive strength test. The specimens were always above the type I Portland cement are those in which the starting material was used as a substituent in $80 \%$ and $90 \%$, which correspond to the geopolymers labeled as GEW-80-8/16 and GEW-90-8/16, respectively. This constraint had already been studied by Wang et al. (2005), checking if one increases the concentration of the components of the activating solution on average of 4 to $12(\mathrm{n} / \mathrm{L})$, the geopolymerization reaction would help to obtain higher compressive strength materials. Geopolymers synthesized using 50\% (GEW$50-8 / 16)$ and $70 \%$ (GEW-70-8/16) of the starting material show a lower performance in the early days of curingwith regard tothose made with whole percentage of type I Portland cement, and their behavior is much higher in the medium- and long-term for curing ages of 21 days for the first of them and 14 days for the second of them.

The most frequent phenomenon in these trials was the fracture of geopolymers in brittle conditions (Figure 4a). However, cases where the cohesion of the material remained almost entirely also presented. Taking into account that all geopolymers were synthesized at the same temperature and curing time (at $70{ }^{\circ} \mathrm{C}$ for $12 \mathrm{~h}$ ), one of the main causes of this fact would have to do in the manner in which the specimens were placed in the testing machine. The maximum value of compressive strength reached for curing ages of 28 days. Therefore, this was the main experimental argument to evaluate the performance and durability of geopolymers in other compressive strength tests (resistance to acids and sulfate attack, and resistance to high temperatures). In general, gold mining wastebased geopolymers show a greater compressive strength than that of type I Portland cementbased mortars.

\subsubsection{Resistance to acid attack}

Once defined that geopolymers with curing ages of 28 days would be subjected to several tests, it was decided to perform testson the compressive resistance of materials after immersing in acidic solutions. The response of the specimens was uniquely different when two types of acids were used. Immersion times in these solutions were 7,21 and 56 days. Results of these tests are summarized in Figure 5. It is noteworthy the negative effect of the $\mathrm{HNO}_{3}$ acid solution, which was much greater than that of the $\mathrm{H}_{2} \mathrm{SO}_{4}$ acid solution. Experimentation 

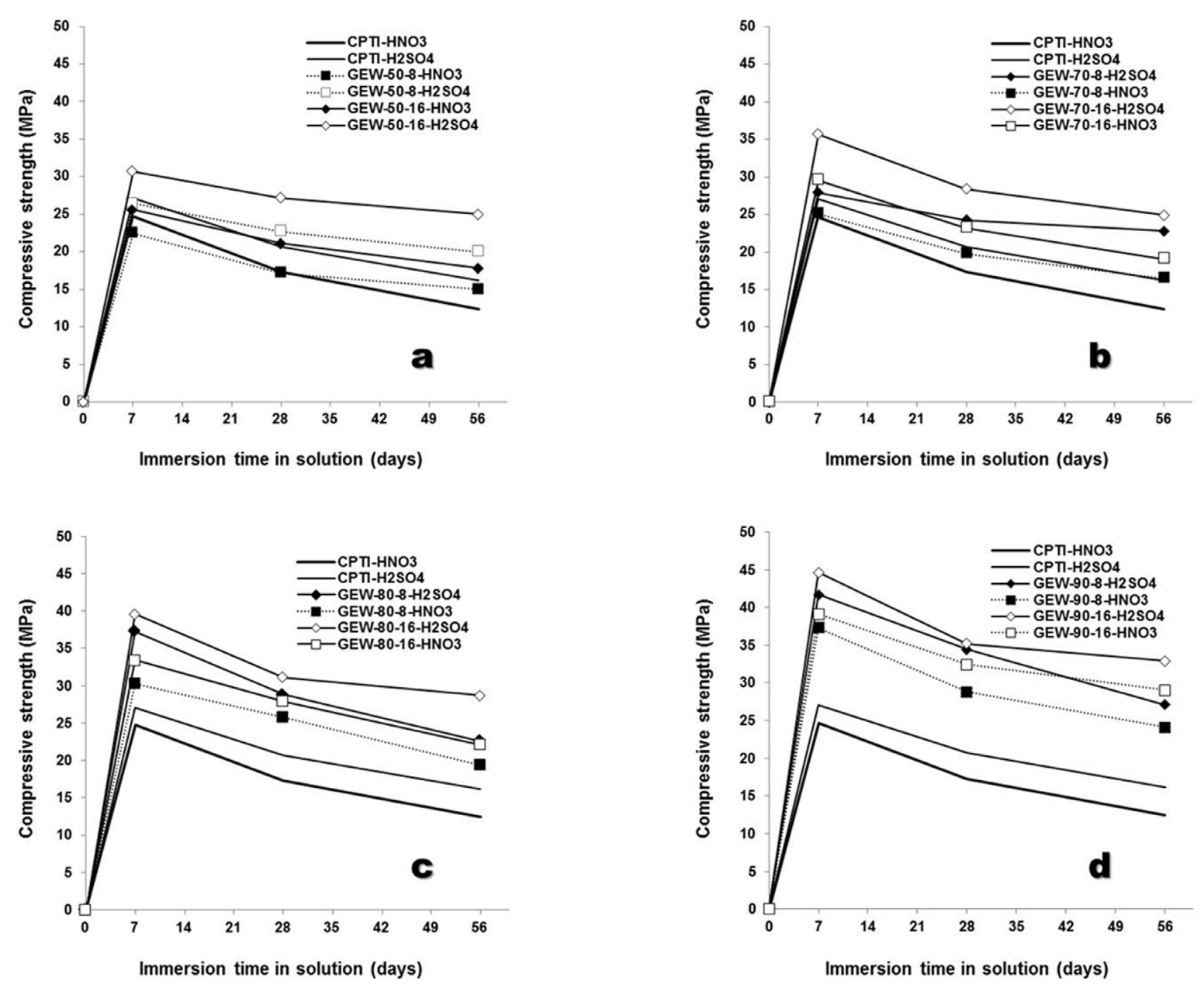

Figure 5. Compressive strength of mortars after acid attack.

showed that during the first days of immersion in both solutions a phenomenon of saturation of the pore space of the geopolymer occurred. At this point, there was a significant change in the weight value of each of the specimens. This physical change produced a slight improvement in the strength of the material itself.

The value of the compressive strength of the specimen that has not been immersed in acid solutions is less compared to that obtained after completion of such immersion. Once more the constraint of chemical type plays an important role in the compressive resistance of materials. Those geopolymers were synthesized with an activating solution of $\mathrm{NaOH}(16 \mathrm{M})$ and $\mathrm{Na}_{2} \mathrm{SiO}_{3}$, showed a better performance with regard to those activated in a solution of $\mathrm{NaOH}(8 \mathrm{M})$ and $\mathrm{Na}_{2} \mathrm{SiO}_{3}$, as suggested by Wang et al. (2005), and which was proved in the rest of results obtained from the performance and durability tests of geopolymers. Although the effect in the shortterm, using either of the two types of acids, it was favorable for the mechanical strength of geopolymers. It is evident that there was an adverse effect in the medium- and longterm. For immersion times in acid solutions of 28 and 56 days, an apparent decrease in the ability of the geopolymer for resisting a compressive load was observed.

In all cases, the cohesion of the material was maintained when tested in sulfuric acid solutions (Figure $4 \mathrm{~b}$ ). A physical change was noted in the specimens as revealed by their dark green to yellowish brown color. This situation was reversed when the specimens were immersed in nitric acid solutions (Figure $4 c)$. In this case, the material was almost entirely corroded after 56 days, undergoing a process of partial brittle fracture of structure. 

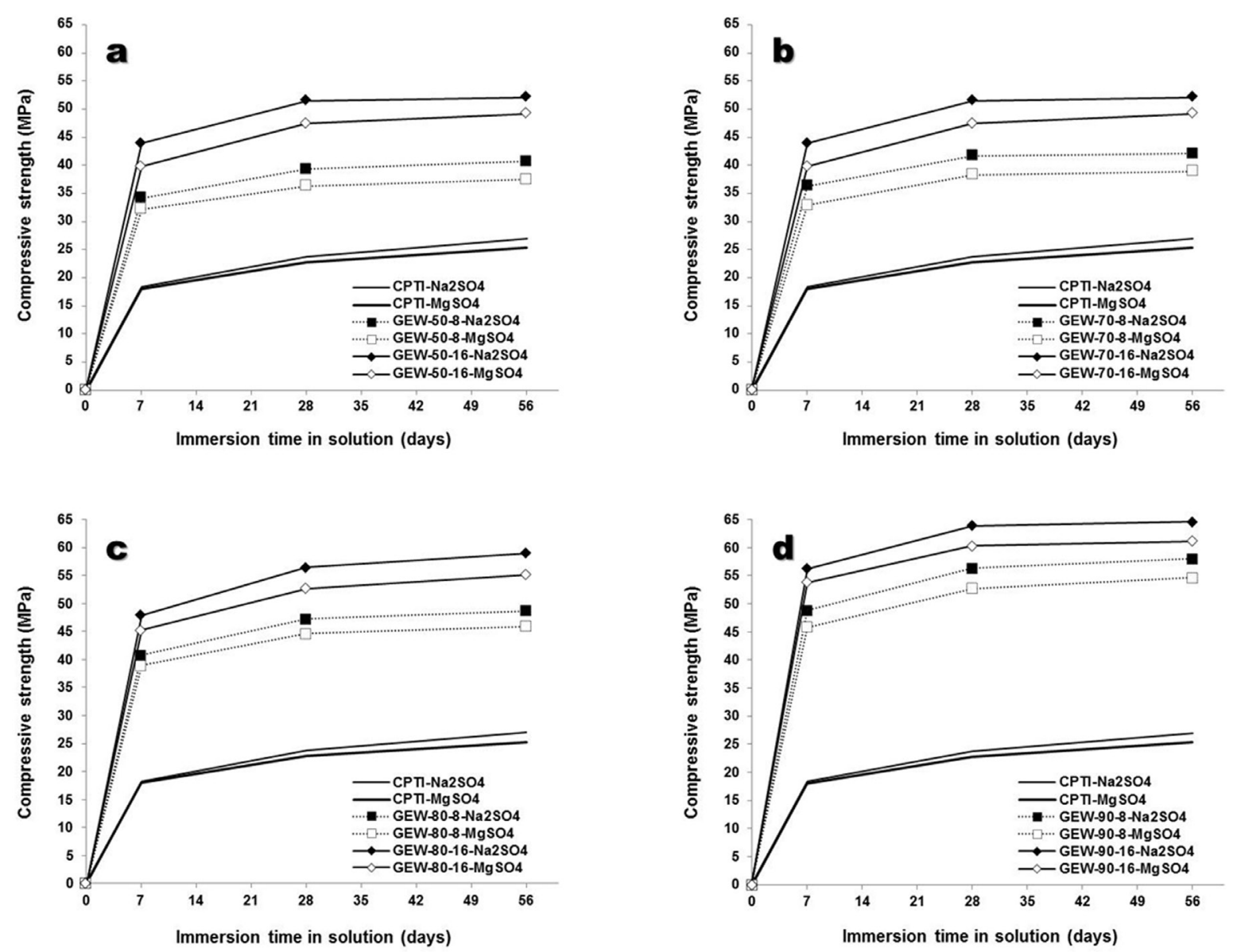

Figure 6. Compressive strength of mortars after sulphate attack.

\subsubsection{Resistance to sulphate attack}

As in the test of compressive resistance to acid attack, geopolymers of curing ages of 28 days were tested to simulate conditions typical of some coastal saline environments. Sulfate solutions of $\mathrm{MgSO}_{4}$ and $\mathrm{Na}_{2} \mathrm{SO}_{4}$ and immersion times of 7,21 and 56 days were also used. Results obtained were unique and different from each other. Figure 6 shows the performance of geopolymers after sulphate attack and reveals a completely different behavior that after acid attack. Contrary to what was expected, considering that we sought to generate an adverse environment for the performance and durability of geopolymers, the tests showed that the sulphate attack increased the mechanical properties of these materials. The general behavior for all tested mortars showed an enrichment of the indigenous capacity of inorganic cements to resist increasingly large compressive loads. In addition to the already proven constraint of chemical type on the favorability of the mechanical properties when an alkaline solution with a molar increase in one of its parts is used, we consider that the gold mining waste is an additive that can increase the durability of the conventional Portland cement in the medium- and long- term.

Unlike the behavior described for the mortars testedunder acid attacks, and regardless of the gold mining waste/type I Portland cement ratio, the performance of geopolymer cements was always higher in each of the experimental periods of time. However, the physical changes caused by the specimens tested at the end of the trials were very different when a specific kind of sulphate used. When the performance and durability test was developed on geopolymers after immersion in a solution of $\mathrm{Na}_{2} \mathrm{SO}_{4}$ at different periods of time, a phenomenon of crystallization of salt occurred (Figure 4d). It is very likely that this crystal growth around most of the specimens has positively affected their mechanical properties. 

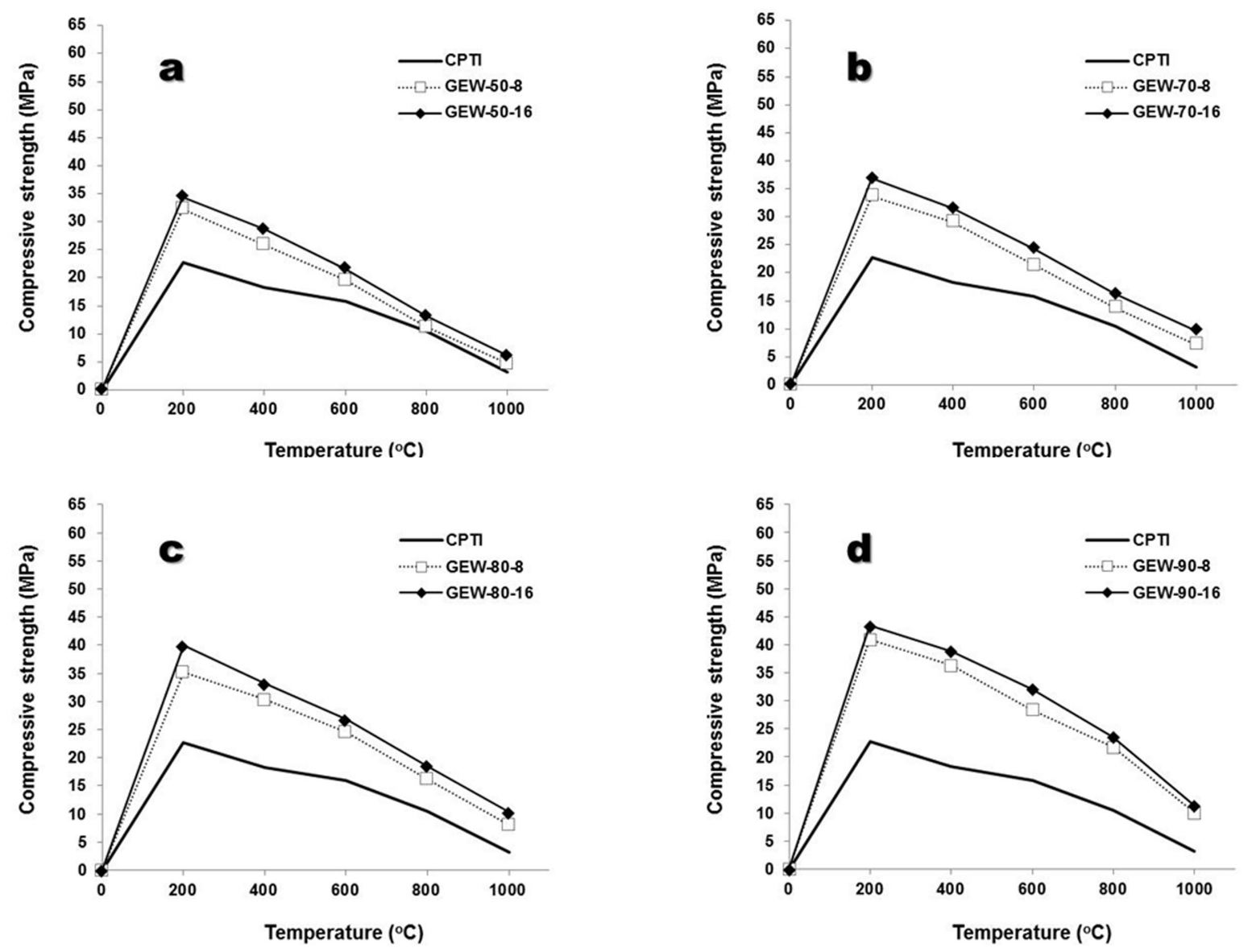

Figure 7. Compressive strength of mortars under high temperatures.

Proportionally to the phenomenon of salt crystallization of salt, there was a progressive increase in the weight of the geopolymer and the compressive strength.A higher increase on of the mechanical properties of the geopolymer was also observed when the solution of $\mathrm{MgSO}_{4}$ was used. Unlike the previous case, there was a phenomenon of crystallization of salt, but on the contrary, there was a complete hardening of the tested geopolymer (Figure 4e). At no time of experimentation brittle fracture phenomena were observed in the materials, another major difference between tests of resistance to acid attacks.

\subsubsection{Resistance to high temperatures}

Figure 7 illustrates the results of the tests of resistance to high temperatures, where an increasingly negative behavior (inversely proportional relationship). It was experimentally determined that the greater the magnitude of the test temperature, the lower themechanical strength of the material. Once more, the synthesized geopolymers with $\mathrm{NaOH}(16 \mathrm{M})$ and $\mathrm{Na}_{2} \mathrm{SiO}_{3}$ show the best performance and durability. As in the test of resistance to sulphate attack, all mortars manifest mechanical strength values that are well above those obtained for type I Portland cement-basedmortars. The geopolymers with higher percentage of substitution (for example those geopolymers labeled as GEW-80-8/16 and GEW-90-8/16) produced higher mechanical strength. Significantly, this particular fact was already registered in the compressive strength tests, and in the tests of resistance to acid and sulphate attack.

The test of resistance to high temperatures is a completely destructive testing and besides the remarkable change in the color of test specimens (Figure 4f), brittle fracture phenomena were observed with temperature increasing.

Therefore, at least is demonstrated from the experimental point of view on a small scale that 
the geopolymeric cements have a higher response regarding to type IPortland cement, whatever the performance and durability test employed. While it is true that conventional cements are materials with high mechanical strength, it was seen that the gold mining waste-based geopolymers are above these routine materials and can be considered as alternative materials with high performance and durability over time.

\section{Conclusions}

Results show that gold mining wastes are suitable in the preparation of geopolymeric products, which are environmental friendly, low production cost, high compressive strength, and excellent performance and long-term durability. This work not only enabling the production of new geopolymers but also contributes to the solution of the environmental concern by mining wastedisposal. The compressive strength test reveal that geopolymers prepared from alkali activation of gold mining wastesshow compressive strength values above those obtained in the commercial Portland cement.Geopolymers prepared from nearly complete replacement of type I Portland cement and cured at $70{ }^{\circ} \mathrm{C}$ for $12 \mathrm{~h}$, shows the higher values of compressive strength. Therefore, these results reveal a real possibility of using gold mining waste-based geopolymers as alternative materials to the type I Portland cement.

\section{Acknowledgements}

This research forms part of the undergraduate thesis of E. Caballero and W. Sánchez. The authors express their gratitude to the Universidad Industrial de Santander for analytical facilities provided for the development of experimental tests as well as its human resources in the assistance of data acquisition.We also acknowledge to the anonymous referees for their critical and insightful reading of the manuscript and are most grateful to the above-named people and institutions for support.

\section{References}

Barcelo, L., \& Kline, J. (2012). The Cement Industry Roadmap to Reduce Carbon Emissions.
Carbon Management Conference, Orlando, Florida (USA), 7-9 February 2012. Available in:http://www.spe.org/events/cmtc/2012/ pages/schedule/tech\%20program/documents/ cmtc152259.pdf

Caballero, E., \& Sánchez, W. (2010). Síntesis de nuevos cementos geopolímeros a partir de subproductos del proceso de extracción de oro en la Mina La Baja, Distrito de California, Santander. Tesis de pregrado, Universidad Industrial de Santander, 103p.

Cheng, T.W., \& Chiu, J.P. (2003). Fireresistant geopolymer produced by granulated blast furnace slag. Minerals Engineering 16, 205-210.

Davidovits, J. (1994). Global warming impact on the cement and aggregates industries. World Resource Review 6, 263-278.

Duxson, P. (2006). The Structure and Thermal Revolution of Metakaolin Geopolymers. Tese de Doutorado. Universidade de Melbourne,Australia.

Duxson, P., Fernández-Jiménez, A., Provis, J.L., Lukey, G.C., Palomo, A., \& van Deventer, J.S.J. (2007). Geopolymer Technology: the current state of the art. Journal of Materials Science 42, 2917-2933.

Fernández-Jimenez, A., \& Palomo, A. (2005). Composition and microstructure of alkali activated fly ash binder: Effect of the activator. Cement and Concrete Research 35, 1984-1992.

Gartner, E. (2004). Industrially interesting approaches to low-CO2 cements.Cement and Concrete Research 34, 1489-1498.

Hauser, A., Eggenberger, U., \&Mumenthaler, T. (1999). Fly ash from cellulose industry as secondary raw material in autoclaved aerated concrete. Cement and Concrete Research 29, 297-302.

Instituto Colombiano de Normas Técnicas ICONTEC. (1998). Método de ensayo para determinar la finura del cemento hidráulico por 
medio de los tamices $75 \mu \mathrm{m}$ (M200) y $150 \mu \mathrm{m}$ (M100). Norma Técnica Colombiana NTC 226.

Instituto Colombiano de Normas Técnicas ICONTEC. (1998). Método para determinar la resistencia a la compresión de morteros de cemento hidráulico usando cubos de $50 \mathrm{~mm}$ de lado. Norma Técnica Colombiana NTC 220.

Instituto Nacional de Vías - INVIAS. (2007). Análisis granulométrico de suelos por tamizado. Norma INV E-123.

Lancellotti, I., Kamseu, E., Michelazzi, M., Barbieri, L., Corradi, A., \&Leonelli, C. (2010). Chemical stability of geopolymers containing municipal solid waste incinerator fly ash. Waste Management 30, 673-679.

Luna-Galiano, Y., Fernández-Pereira, C.,\&Vale, J. (2011). Stabilization/solidification of a municipal solid waste incineration residue using fly ash-based geopolymers. Journal of Hazardous Materials 185, 373-381.

Pacheco-Torgal, F., Castro-Gomes, J., \& Jalali, S. (2007). Investigations about the effect of aggregates on strength and microstructure of geopolymeric mine waste mud binders. Cement and Concrete Research 37, 933-941.

Pacheco-Torgal, F., Castro-Gomes, J., \& Jalali, S. (2008). Properties of tungsten mine waste geopolymeric binder. Construction and Building Materials 22, 1201-1211.

Puertas, F., Blanco-Varela, M.T., \& Vazquez, T. (1999). Behaviour of cement mortars containing an industrial waste from aluminium refining. Stability in $\mathrm{Ca}(\mathrm{OH}) 2$ solutions. Cement and Concrete Research 29, 1673-1680.

Puertas, F., Barra, A., Gazulla, M.F., Gomez, M.P., Palacios, M., \& Martinez, S. (2006). Ceramic wastes as raw materials in Portland cement clinker fabrication: characterization and alkaline activation. Materiales de Construccion 56, 73-84.

Pérez, L. (2008). Ensayo metodológico para la caracterización automatizada de menas metálicas mediante análisis digital de imagen. Aplicación geometalúrgica. Revista del Instituto de Investigación de la Facultad de Ingeniería Geológica, Minera, Metalúrgica y Geográfica 11, 55-60.

Riaza, A., Escuder, J., Villar, P., \& MartínAlfageme, S. (1994). Reflectancia espectral en el visible e infrarrojo cercano $(400-2500 \mathrm{~nm})$ de distintas litologías en un conjunto ígneo y metamórfico (Salamanca, España): aplicaciones en cartografía geológica. Instituto Tecnológico Geominero de España 7, 7-20.

Rojas-López, R., Delgado-Macui, R., DíazReyes, J., Rojas-Luna, R.I., Olvera-Hernández, J., Salazar-Hernández, B., \& Muñoz, N. (2006). Espectroscopia de reflectancia difusa en el mediano infrarrojo para el análisis de arcillas de cerámica talavera. Congreso Iberoamericano de Metalurgia y Materiales. Habana, Cuba.

Singh, M., \& Garg, M. (2000). Making of anhidrite cement from waste gypsum.Cement and Concrete Research 27, 1203-1212.

Shih, P.H., \& Yokohama, S. (2003). Behaviour of chloride ions in hardened ecocement: New type of Portland cement made from municipal waste incinerator ash. 11th ICCC, Durban, 1271-1281.

Soares, P., Pinto, A.T., Ferreira, V.M., \& Labrincha, A.J. (2008). Geopolymerization of lightweight aggregate waste. Materiales de Construcción 58, 23-34.

Temuujin, A., Rickard, W., \& Van Riessen, A. (2013). Characterization of various fly ashes for preparation of geopolymers with advanced applications. Advanced Powder Technology 24, 495-498.

USGS (2012). Cement. Available in: http:// minerals.usgs.gov/minerals/pubs/commodity/ cement/mcs-2012-cemen.pdf

Van Riessen, A., Jamieson, E., Kealley, C.S., Hart, R.D., \& Williams, R.P. (2013). Bayergeopolymers: An exploration of synergy between the alumina and geopolymer industries. Cement and Concrete Composites 41, 29-33. 
Wang, H., Li, H., \& Yang, F. (2005). Synthesis and Tribological Behavior of Metakaolinite Based Geopolymers Composites. Materials letters 59, 3976-3981.
Zhang, L., Ahmari, S., \& Zhang, J. (2011). Synthesis and characterization of fly ash modified mine tailings-based geopolymers. Construction and Building Materials 25, 3773-3781. 